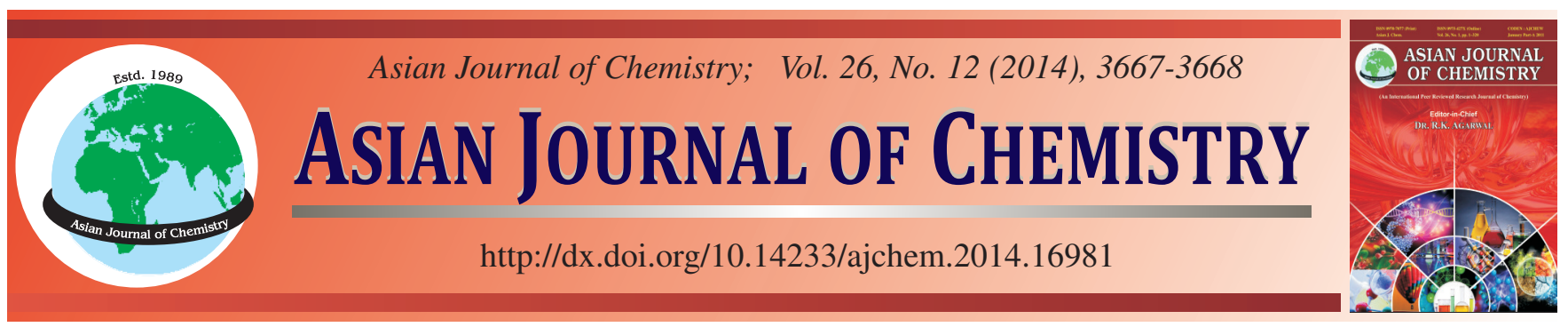

NOTE

\title{
Solvent Evaporation Method and Crystal Structure of [5-Benzoyl-2-methyl-4-(1- phenyl[1,2,3]triazolidin-4-ylmethoxy)benzofuran-7-yl]phenyl-methanone
}

\section{ZHANG ${ }^{1, *}$ and Y.X. HE ${ }^{2}$}

${ }^{1}$ College of Chemistry and Chemical Engineering, Luoyang Normal University, Henan, P.R. China

${ }^{2}$ College of Chemical Engineering and Pharmaceutics Henan University of Science and Technology, Henan, P.R. China

*Corresponding author: Tel/Fax: +86 379 65515113, E-mail: zhanglihxx@ 126.com

One new compound i.e., [5-benzoyl-2-methyl-4-(1-phenyl[1,2,3]triazolidin-4-ylmethoxy)benzofuran-7-yl]phenyl-methanone with m.f. $\mathrm{C}_{32} \mathrm{H}_{23} \mathrm{~N}_{3} \mathrm{O}_{4}$ has been successfully synthesized by 1-azidobenzene, the appropriate alkyne, copper sulphate and sodium ascorbate. Compound shows a one-dimensional framework. The 3D supramolecular structure is formed via hydrogen bonding connection.

Keywords: Sodium ascorbate, Crystal structure, Methanone.

Metal organic frameworks (MOFs) have received much attention in the field of crystal engineering and supramolecular chemistry because of their diverse structures and promising applications in functional materials such as luminescent materials, gas adsorption and magnetism ${ }^{1-4}$. Hydrogen bonds are well suited for the design of polymeric arrangement and crystal engineering because of their important directional interactions and because they can interlink 1-D, or 3-D structures into higher-dimensionality systems ${ }^{5,6}$.

All reagent and solvents employed were commercially available and used as received without further purification.

A mixture of the 1-azidobenzene ( $2 \mathrm{mmol})$, the appropriate alkyne $(2 \mathrm{mmol})$, copper sulphate $(0.025 \mathrm{mmol})$ and sodium ascorbate $(0.5 \mathrm{mmol})$ in $6 \mathrm{~mL}$ of $t-\mathrm{BuOH} / \mathrm{H}_{2} \mathrm{O}(1: 1)$ was stirred at $65{ }^{\circ} \mathrm{C}$ overnight. The crude products precipitate upon adding water and were purified by chromatograpy recrystallized from $\mathrm{EtOH} / \mathrm{H}_{2} \mathrm{O}$. Finally colourless crystals were formed.

Detection method: Diffraction intensity data of the single crystal of the compound was collected on a Bruker SMART APEX-II CCD diffractometer equipped with a graphite monochromated $\mathrm{MoK}_{\alpha}$ radiation $(\lambda=0.71073 \AA$ ) by using a $\omega$-scan mode. All the structures were solved by direct methods and refined by full-matrix least-squares methods on $\mathrm{F}^{2}$ using the program SHEXL $97^{7}$. All non-hydrogen atoms were refined anisotropically. The hydrogen atoms were located by geometrically calculations and their positions and thermal parameters were fixed during the structure refinement. The crystallographic data and experimental details of structural analyses for coordination polymers are summarized in Table-1. Selected bond and angle parameters are listed in Table- 2 .

The crystal structure determined by X-ray diffraction reveals is [5-benzoyl-2-methyl-4-(1-phenyl[1,2,3]triazolidin4-ylmethoxy)benzofuran-7-yl]phenyl-methanone. The bond connecting the benzene ring and the triazole ring is a single bond, which can rotate and the bond length of $\mathrm{N}(1)-\mathrm{C} 1$ is 1.420(3) $\AA$, in addition. The dihedral angle between the benzene ring $\mathrm{C} 19$ to $\mathrm{C} 24$ and the benzene ring $\mathrm{C} 26$ to $\mathrm{C} 31$ is

\begin{tabular}{ll}
\multicolumn{2}{c}{ TABLE-1 } \\
\multicolumn{1}{c}{ CRYSTALLOGRAPHIC DATA AND } \\
\multicolumn{1}{c}{ STRUCTURE REFINEMENT SUMMARY } \\
\hline Empirical formula & $\mathrm{C}_{32} \mathrm{H}_{23} \mathrm{~N}_{3} \mathrm{O}_{4}$ \\
Formula weight & 513.53 \\
Crystal system space group & Triclinic, $\mathrm{P}-1$ \\
Unit cell dimensions & $\mathrm{a}=10.019(10) \AA$ \\
& $\mathrm{b}=10.819(11) \AA$ \\
& $\mathrm{c}=11.554(12) \AA$ \\
Volume $\left(\AA^{3}\right)$ & $1246(2)$ \\
$\theta$ range for data collection & $2.48-25.50$ \\
Final $\mathrm{R}$ indices $[\mathrm{I}>2 \sigma(\mathrm{I})]$ & $\mathrm{R}_{1}=0.0485, \mathrm{wR}_{2}=0.1155$ \\
$\mathrm{Z}$, Calculated density $\left(\mathrm{mg} / \mathrm{m}^{3}\right)$ & $2,1.368$ \\
Absorption coefficient $\left(\mathrm{mm}{ }^{-1}\right)$ & 0.092 \\
F(000) & 536 \\
Limiting indices & $-12 \leq \mathrm{h} \leq 11 ;-12 \leq \mathrm{k} \leq 13 ;$ \\
& $-13 \leq l \leq 13$ \\
Largest diff. peak and hole $\left(\mathrm{e} / \AA^{3}\right)$ & 0.282 and- 0.464 \\
Goodness-of-fit on $\mathrm{F}^{2}$ & 0.991 \\
$\mathrm{R}$ indices (all data) & $\mathrm{R}_{1}=0.0763 ; \mathrm{wR}_{2}=0.1337$ \\
\hline
\end{tabular}


TABLE-2

SELECTED BOND LENGTHS $(\AA)$ AND ANGLES $\left({ }^{\circ}\right)$

\begin{tabular}{llll}
\hline $\mathrm{N}(1)-\mathrm{N}(2)$ & $1.366(3)$ & $\mathrm{N}(1)-\mathrm{C}(7)$ & $1.355(3)$ \\
$\mathrm{N}(2)-\mathrm{N}(3)$ & $1.305(3)$ & $\mathrm{N}(1)-\mathrm{C}(1)$ & $1.420(3)$ \\
$\mathrm{O}(1)-\mathrm{C}(10)$ & $1.365(3)$ & $\mathrm{N}(3)-\mathrm{C}(8)$ & $1.371(3)$ \\
$\mathrm{C}(7)-\mathrm{N}(1)-\mathrm{N}(2)$ & $109.96(19)$ & $\mathrm{N}(3)-\mathrm{N}(2)-\mathrm{N}(1)$ & $107.04(19)$ \\
$\mathrm{C}(7)-\mathrm{N}(1)-\mathrm{C}(1)$ & $130.44(19)$ & $\mathrm{N}(2)-\mathrm{N}(3)-\mathrm{C}(8)$ & $109.24(19)$ \\
$\mathrm{N}(2)-\mathrm{N}(1)-\mathrm{C}(1)$ & $119.53(19)$ & $\mathrm{C}(10)-\mathrm{O}(1)-\mathrm{C}(9)$ & $118.06(18)$ \\
$\mathrm{C}(12)-\mathrm{O}(4)-\mathrm{C}(17)$ & $106.03(17)$ & $\mathrm{C}(6)-\mathrm{C}(1)-\mathrm{N}(1)$ & $121.2(2)$ \\
\hline
\end{tabular}

$60.75^{\circ}$. The dihedral angle between the benzene ring $\mathrm{C} 19$ to $\mathrm{C} 24$ and the benzene ring $\mathrm{C} 1$ to $\mathrm{C} 6$ is $8.61^{\circ}$. The dihedral angle between the benzene ring $\mathrm{C} 19$ to $\mathrm{C} 24$ and the triazole ring C7 N1 N2 N3C8 is $12.73^{\circ}$. The dihedral angle between the benzene ring $\mathrm{C} 19$ to $\mathrm{C} 24$ and the benzene ring $\mathrm{C} 10$ to $\mathrm{C} 15$ is $66.48^{\circ}$ (Fig. 1). The chains are further assembled by the intermolecular hydrogen bonding interaction leading to the formation of a 3D framework (Fig. 2).

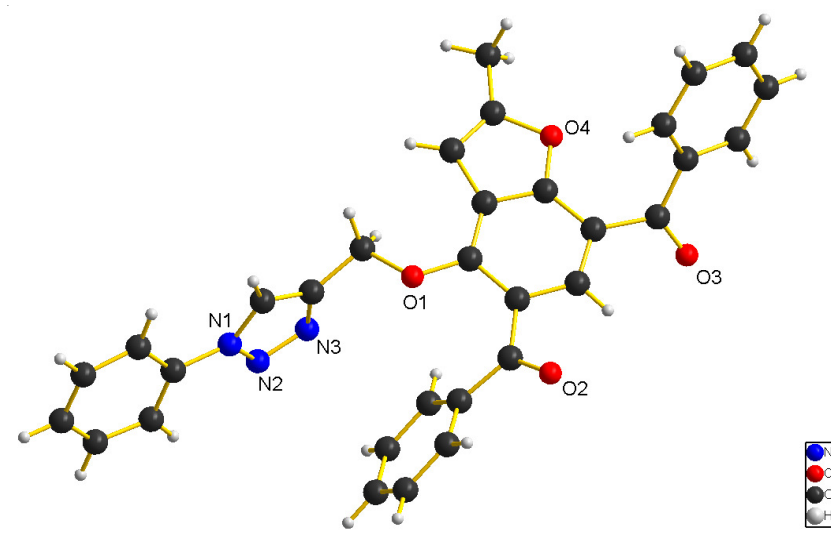

Fig. 1. Molecular structure of the title compound at $30 \%$ probability displacement ellipsoids

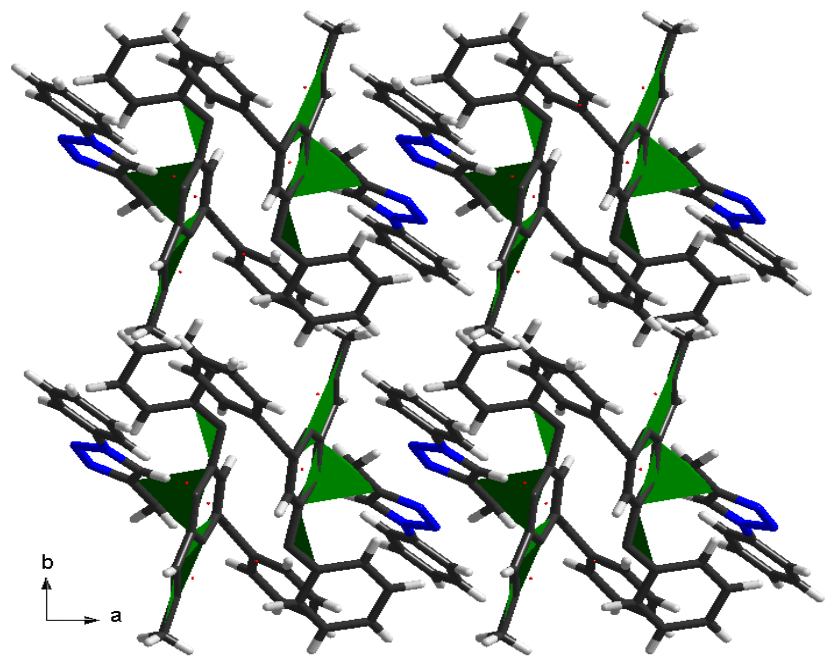

Fig. 2. 3D structure formed via hydrogen bonding interactions

\section{REFERENCES}

1. B.O. Patrick, C.L. Stevens, A. Storr and R.C. Thompson, Polyhedron, 24, 2242 (2005).

2. Y.H. Wen, J.K. Cheng, Y.L. Feng, J. Zhang, Z.L. Li and Y.G. Yao, Inorg. Chim. Acta, 358, 3347 (2005).

3. X.L. Wang, C. Qin, E.B. Wang and L. Xu, J. Mol. Struct., 749, 45 (2005).

4. S.R. Batten and K.S. Murray, Coord. Chem. Rev., 246, 103 (2003).

5. T.L. Hu, R.Q. Zou, J.R. Li and X.H. Bu, J. Chem. Soc., Dalton Trans., 1302 (2008).

6. J.F. Song, Y. Chen, Z.G. Li, R.S. Zhou, X.Y. Xu and J.Q. Xu, J. Mol. Struct., 842, 125 (2007).

7. G.M. Sheldrick, SHELXTL97, Program for the Refinement of Crystal Structure, University of Gottingen, Germany (1997). 